\title{
HUBUNGAN SANITASI KANDANG DENGAN KEPADATAN LALAT DI KECAMATAN SOKARAJA
}

\author{
Alfian Giffari Novia Ardi ${ }^{1)}$, Budi Triyantoro" ${ }^{1)}$, Teguh Widiyanto ${ }^{1)}$ \\ 1) Poltekkes Kemenkes Semarang
}

\begin{abstract}
Abstrak
Kesehatan lingkungan adalah suatu kondisi lingkungan yang mampu menopang keseimbangan dinamis antara manusia dan lingkungan, serta melindungi kesehatan manusia melalui pencegahan penyakit yang diakibatkan oleh lingkungan. Salah satu vektor penyakit yang sering menimbulkan masalah dalam lingkungan, yaitu lalat. Lalat sangat menyukai tempat yang kotor, salah satunya adalah kandang ternak. Kandang sapi juga pada umumnya kotor dan berbau, sehingga lalat banyak dijumpai di kandang ter-sebut, seperti lalat rumah (Musca domestica). Tujuan Penelitian yaitu untuk menganalisis hubungan sanitasi kandang dengan kepadatan lalat di Kecamatan Sokaraja Kabupaten Banyumas. Jenis penelitian ini adalah observasional yang bersifat dengan pendekatan Cross Sectional, penelitian ini dilakukan pada peternakan sapi yang ada di Kecamatan Sokaraja, untuk menilai sanitasi kandang sapi dan menganalisis kepadatan lalat di kandang sapi. Hasil observasi menunjukkan 10 kandang sapi, terdapat 7 kandang sapi yang memenuhi syarat dan 3 kandang yang tidak memenuhi syarat, sedangkan kepadatan lalat menunjukkan bahwa dari 10 kandang sapi terdapat 10 kandang sapi dengan kepadatan lalat sedang. Hasil analisis menggunakan uji Korelasi Sperman rank Korelasi Koefisien sebesar 0,076 $>0,05$ artinya HA ditolak dan H0 diterima, yang berarti tidak ada hubungan sanitasi kandang dengan kepadatan lalat di kandang sapi, dari 10 kandang sapi terdapat 3 kandang tidak memenuhi syarat sanitasi. Kepadatan lalat di kandang sapi dikategorikan sedang sampai dengan tinggi. Perlu adanya, upaya meningkatkan sanitasi kandang sapi dalam hal pemberian desinfeksi, penggunaan APD, pencegahan kepadatan lalat, pembersihan kandang, pengelolaan limbah.
\end{abstract}

Kata Kunci: Santiasi Kandang, Kepadatan Lalat di Kandang Sapi

\begin{abstract}
[Title: Sanitation Relationship With The Degree Of Cattle Flat In Subdistrict Sokaraja, Banyumas District, 2019]

Environmental health is an environmental condition that can support the dynamic balance between humans and the environment, and protect human health through prevention of diseases caused by the environment. One vector of diseases that often causes problems in the environment, namely flies. Flies really like dirty places, one of which is livestock cages. Cow cages are also generally dirty and smelly, so flies are often found in the cage, such as house flies (Musca domestica). The research objective was to analyze the relationship of cage sanitation with fly density in Sokaraja Subdistrict, Banyumas Regency. The type of this research is Observational with Cross Sectional approach, this research was conducted on cattle farms in Sokaraja Subdistrict, to assess cattle cage sanitation and analyze the density of flies in cow pens. Observation results showed that 10 cow cages had 7 cattle cages that fulfilled the requirements and 3 cages that did not meet the requirements, while fly densities showed that from 10 cow cages there were 10 cages with medium fly density. The results of the analysis using Sperman rank, Korelasi Koefisiaen $0.76>0.05$ which means that HO is accepted which means there is no relationship between sanitation cages and the density of flies in cattle pens. The relation of cattle cage sanitation in Sokaraja Subdistrict, Banyumas Regency, out of 10 cattle cages there are 3 cages that do not meet sanitation requirements. The density of flies in cattle cages is categorized as moderate to high. There needs to be an effort to improve cattle shed sanitation in terms of disinfection, use of PPE, prevention of density of flies, cleaning of cages, waste management.
\end{abstract}

Keywords: Cattle Sanitation. Flies Density in Cow Cages

\section{Pendahuluan}

Kesehatan lingkungan adalah suatu kondisi lingkungan yang mampu menopang keseimbangan ekologis yang dinamis antara manusia dan lingkungan untuk mendukung tercapainya realitas hidup yang sehat dan seni mengelolah lingkungan 
agar bisa menciptakan kondisi lingkungan yang bersih, sehat, nyaman dan aman serta terhindar dari berbagai macam penyakit, serta melindungi kesehatan manusia melalui pencegahan penyakit yang diakibatkan oleh lingkungan (Sumengen Sutomo, 2001).

Upaya pencegahan penyakit dan/ atau gangguan kesehatan dari faktor risiko lingkungan untuk mewujudkan kualitas ling-kungan yang sehat baik dari aspek fisik, kimia, biologi, maupun sosial merupakan salah satu kegiatan kesehatan lingkungan. Salah satu kegiatannya adalah pengendalian vektor penyakit (PP RI No. 66 Tahun 2014).

Salah satu vektor penyakit yang sering menimbulkan masalah dalam ling-kungan masyarakat, yaitu lalat. Lalat adalah salah satu insekta yang termasuk ordo Dhiptera, yakni insekta yang mempunyai sepasang sayap berbentuk membran. Pada saat ini, banyak spesies lalat yang sering dijumpai oleh manusia. Tentu saja tidak semua spesies lalat berbahaya bagi manusia, ditinjau dari sudut kesehatan lingkung-an. Jumlah spesies lalat yang paling penting hanya beberapa saja, yaitu lalat rumah (Musca domestica), lalat kandang (Stomoxys calcitrans), lalat hijau (Phenesia), lalat daging (Sarcoplaga), dan lalat kecil (Fan nia) (Azwar, 1995).

Menurut YuIiarsi (2002), bahwa jumlah populasi lalat yang tinggi (kepadatan tinggi) dapat menimbulkan gangguan kenyamanan bagi masyarakat. Kepadatan lalat merupakan masalah penting, karena lalat merupakan salah satu vektor penyakit secara mekanis, (Mecanical transmition). Disebut vektor mekanis, karena lalat menyebarkan penyakit, kuman (bibit penyakit) menempel pada kaki, bulu, sayap, badan dan ikut tersebar saat lalat terbang dan hinggap. Apabila lalat hinggap pada kotoran ternak, maka lalat akan meninggalkan telur yang tertinggal pada makanan bibit penyakit (kuman) akan ter-tinggal pada makanan tersebut dan apabila termakan oleh manusia, maka akan menim-bulkan penyakit.

Menurut Depkes RI (1992), penyakit yang diakibatkan oleh lalat antara lain Disentri, Diare dan Cholera. Disentri yang merupakan peradangan usus besar yang ditandai dengan sakit perut dan buang air besar berulang-ulang yang bercampur lendir atau darah, sehingga menyebabkan penderita kehilangan banyak cairan dan darah, penyakit yang kedua adalah Diare, penyakit yang buang air besar dalam bentuk cairan lebih dari 3 kali dalam 1 hari dan biasanya berlangsung lebih dari 2 hari, diare dapat menyebabkan dehidrasi (kekurangan cairan) atau masalah gizi yang parah. Diare disebabkan oleh bakteri yang dibawa oleh lalat, selanjutnya mengkontaminasi bakteri ke maka-nan manusia, penyakit yang ketiga yaitu Cholera, penyakit Cholera, yaitu penyakit diare akut yang disebabkan oleh infeksi usus akibat terkena bakteri Vibrio Cholerae, bakteri ini masuk ke dalam tubuh seseorang melalui makanan atau mi-numan yang terkontaminasi serta tinja orang yang telah terinfeksi. Kesehat-an perorangan yang buruk serta sanitasi lingkungan yang tidak baik mempunyai pe-ranan langsung terhadap kejadian 3 penyakit diatas .

Sanitasi lingkungan yang tidak baik antara lain pada lingkungan yang terdapat kandang ternak. Pada umumnya kandang sapi tidak terpelihara sanitasinya, sehingga kotor, bau dan terdapat banyak lalat. Upaya kesehatan yang dapat dilakukan adalah dengan cara memelihara dan melindungi kebersihan ling-kungan dari subyeknya. Misalnya menye-diakan air yang bersih untuk keperluan men-cuci tangan, menyediakan tempat sampah untuk menampung sampah agar tidak dibuang sembarangan (Kemenkes RI, 2004). Sanitasi kandang adalah suatu kegiatan yang meliputi kebersihan kandang dan lingkungannya, karena dengan keadaan kandang serta lingkungan yang bersih, kesehatan ternak maupun pemi-liknya akan terjamin. Kebersihan kandang diatur sesuai dengan kebutuhan, sehingga lingkungan tidak berbau dan lembab (Sarwono, 2012).

Penelitian ini bertujuan untuk menge-tahui Hubungan Sanitasi Kandang Kepadatan Lalat di Kecamata Sokaraja

\section{Bahan dan Metode}

Jenis penelitian ini adalah Obser-vasional yang bersifat dengan pendekatan Cross Sectional, penelitian ini dilakukan pada 10 kandang sapi yang ada di Kecamatan Sokaraja, untuk menilai sanitasi di kandang-kandang sapi dan menganalisis kepadatan lalat di kandang-kandang sapi.

\section{Hasil dan Pembahasan Data Umum}

a. Lokasi Kandang

Lokasi penelitian ini berada di 10 kandang sapi di desa yang berbeda yang ada di Kecamatan Sokaraja Kabupaten Banyumas. Berdasarkan pengamatan peneliti terhadap kandang sapi yang ada, di setiap kandang memiliki luas berbeda, serta kondisi kan-dang yang berbeda pula. Berdasarkan observasi kandang sapi terdapat 3 kandang yang lokasinya kurang dari 10 meter atau dekat dengan pemukiman penduduk dan 7 kandang jauh dari pemukiman penduduk yang berjarak lebih dari 10 meter, ke-7 kandang tersebut berada di lokasi sawah dan kebun, untuk akses kandang sapi terdapat 2 kandang sapi yang akses keluar masuk kandang sulit dikarenakan kandang tersebut berada di dalam gang, sehingga menyulitkan aktifitas keluar masuk sapi dan menggangu aktifitas warga sekitar kandang sapi tersebut, sedangkan ke-8 kandang sapi aksesnya mudah dikarenakan berada di samping jalan yang dapat dilalui oleh transportasi untuk sapi.

Menurut Ainur Rasyid Hartati (2007), persyaratan kandang sapi yang perlu diperhatikan yaitu jarak kandang harus terpisah dengan rumah 
penduduk, dengan jarak lebih dari 10 meter dan akses kandang sapi tersebut mudah dilalui. Terdapat 3 kandang sapi yang jaraknya kurang dari 10 meter dan 2 kandang sapi yang aksesnya sulit dilalui dikarenakan kandang tersebut berada di gang sempit, agar ke-3 kandang tersebut memenuhi syarat diharuskan kandang tersebut dipindahkan yang jaraknya lebih dari 10 meter dan 2 kandang harus dipindahkan ke tempat yang aksesnya mudah dilalalui, atau jangan berada di gang sempit.

b. Kondisi Kandang

Berdasarkan pengamatan peneliti terdapat 3 kandang yang kondisinya bau dan kotor, tidak ada tempat penampungan kotoran serta lokasi kandang tersebut berada di dekat pemukiman penduduk, dikarenakan lokasinya dekat dengan pemukiman penduduk, sehingga bau kotoran dapat mencemari udara sekitar kandang yang dapat mengakibatkan bau tidak sedap yang menyebar ke pemukiman warga.

Menurut Ainur Rasyid Hartati (2007) persyaratan yang perlu diketahui untuk ke-3 kandang sapi tersebut yaitu membuat pembuangan kotoran, setiap hari kotoran harus dibersihkan, setiap hari kandang harus dibersihkan agar kandang tidak kotor dan bau, sehingga tidak terjadi pencemaran udara di sekitar kandang sapi.

\section{Data Khusus}

a. Sanitasi Kandang

Tabel 1: Syarat nilai sanitasi kandang sapi yaitu harus diatas 70\%. Hasil Observasi Sanitasi Kandang :

\begin{tabular}{|c|c|c|}
\hline No & $\begin{array}{c}\text { Nama } \\
\text { Pemilik } \\
\text { Kandang }\end{array}$ & $\begin{array}{c}\text { Kategori } \\
\text { Sanitasi } \\
\text { Kandang Sapi }\end{array}$ \\
\hline 1. & A & $\begin{array}{l}90 \text { (memenuhi } \\
\text { syarat) }\end{array}$ \\
\hline 2. & B & $\begin{array}{c}90 \text { (memenuhi } \\
\text { syarat) } \\
66 \text { (tidak }\end{array}$ \\
\hline 3. & $\mathrm{C}$ & $\begin{array}{c}\text { memenuhi } \\
\text { syarat) }\end{array}$ \\
\hline 4. & D & $\begin{array}{c}87 \text { (memenuhi } \\
\text { syarat) }\end{array}$ \\
\hline 5. & $\mathrm{E}$ & $\begin{array}{l}\text { memenuhi } \\
\text { syarat) }\end{array}$ \\
\hline 6. & $\mathrm{~F}$ & $\begin{array}{l}83 \text { (memenuhi } \\
\text { syarat) }\end{array}$ \\
\hline 7. & $\mathrm{G}$ & $\begin{array}{l}87 \text { (memenuhi } \\
\text { syarat) }\end{array}$ \\
\hline 8. & $\mathrm{H}$ & $\begin{array}{l}77 \text { (memenuhi } \\
\text { syarat) }\end{array}$ \\
\hline 9. & I & $\begin{array}{c}66 \text { (tidak } \\
\text { memenuhi } \\
\text { syarat) }\end{array}$ \\
\hline 10. & $\mathrm{~J}$ & $\begin{array}{l}83 \text { (memenuhi } \\
\text { syarat) }\end{array}$ \\
\hline
\end{tabular}

Berdasarkan Hasil observasi sanitasi kandang sapi, bahwa dari 10 kandang sapi terdapat 7 (70\%) kandang sapi mendapatkan nilai diatas $70 \%$ atau sanitasi kandang yang memenuhi syarat, dari ketujuh kandang yang memenuhi syarat mendapatkan nilai 77 $\%$ sampai $90 \%$ dan terdapat $3(30 \%)$ kandang sapi masih dibawah $70 \%$ atau sanitasi kandang yang tidak memenuhi syarat, ketiga kandang yang tidak memenuhi syarat mendapatkan nilai $66 \%$.

Sanitasi kandang ternak merupakan tindakan pengendalian penyakit melalui kebersihan. Oleh karena itu untuk memperoleh lingkungan yang bersih, higienis dan sehat tindakan sanitasi harus dilaksanakan dengan teratur. Rendahnya sanitasi dapat menimbulkan berkembangnya suatu penyakit. Faktor-faktor yang menunjukan keadaan sanitasi di kandang yang tidak memenuhi syarat yaitu:

1) Intensitas Cahaya

Berdasarkan pengukuran pencaha-yaan kandang sapi menggunakan Lux meter yang dilakukan pengukuran pada 10 kandang sapi. Hasil pengukuran intensitas cahaya pada masing-masing kandang yaitu, 55 Lux yang terendah dan yang tertinggi dalam pengukuran pencahayaan dikandang sapi 95 Lux, sedangkan syarat pencahayaan di kandang sapi yaitu 60 Lux.

Terdapat 8 kandang sapi yang pencahayaannya sudah memenuhi syarat, yaitu 60 lux, dan terdapat 2 kandang sapi yang belum memenuhi syarat kandang sapi dikarenakan pencaha-yaan kandang tersebut masih dibawah 60 Lux sehingga kandang tersebut masih gelap dan susah untuk melakukan aktifitas di kandang sapi seperti peng-lihatannya yang kurang pada saat di kandang sapi, agar ke-2 kandang tersebut memenuhi syarat penca-hayaan disarankan kandang tersebut dibikin pencahayaan buatan agar memudahkan pekerja kandang melakukan aktifitas di kandang sapi.

2) Suhu dan Kelembaban

Berdasarkan pengukuran hasil pengu-kuran suhu dan kelembaban meng-gunakan Hygrometer yang dilakukan pengu-kuran pada masing-masing kandang sapi mempe-roleh hasil pengukuran suhu $27{ }^{\circ} \mathrm{C}$ sebagai suhu yang terendah dan $29{ }^{\circ} \mathrm{C}$ sebagai suhu yang tertinggi suhu, sedangkan hasil pengu-kuran kelembaban pada masing-masing kandang sapi yaitu, $60 \%$ sebagai kelem-baban terendah dan $61 \%$ kelembaban tertinggi. Syarat suhu kelembaban kandang sapi yaitu $27{ }^{\circ} \mathrm{C}$ dan $60 \%$, tetapi syarat tersebut tidak mempengaruhi kehidupan lalat dan dapat terbang di kandang sapi.

Menurut Ditjen PPM dan PP (1991), lalat mulai terbang pada suhu 15 Co dan aktifitas optimumnya pada suhu $210 \mathrm{O}$, pada suhu dibawah 7,5 OC lalat tidak aktif dan di atas 45 OC terjadi kematian pada lalat, sedangkan untuk kelembaban mengikuti suhu tempat sekitar, jadi 10 kandang tersebut masih bisa ditemukan kehidupan lalat. 
Agar berkurangnya kehidupan lalat di kandang sapi yaitu dilakukan membersihkan kandang dan sapi setiap harinya agar lalat berkurang.

b. Kepadatan Lalat

Tabel 2: Penilaian kepadatan lalat dikandang sapi pada 10 kandang sapi yang ada di Kecamatan Sokaraja Kabupaten Banyumas dengan menggunakan Cheklist.

\begin{tabular}{ccc}
\hline No. & $\begin{array}{c}\text { Nama Pemilik } \\
\text { Kandang }\end{array}$ & $\begin{array}{c}\text { Jumlah Kepadatan Lalat } \\
\text { di Kandang Sapi }\end{array}$ \\
\hline 1. & A & 4 (sedang) \\
2. & B & 4 (sedang) \\
3. & C & 5 (sedang) \\
4. & D & 5 (sedang) \\
5. & E & 4 (sedang) \\
6. & F & 4 (sedang) \\
7. & G & 5 (sedang) \\
8. & H & 4 (sedang) \\
9. & I & 4 (sedang) \\
10. & J & 4 (sedang) \\
\hline
\end{tabular}

Berdasarkan hasil observasi kepadatan lalat di kandang menunjukkan bahwa dari 10 kandang sapi terdapat 7 kandang sapi dengan kepadatan lalat sedang dan terdapat 3 kandang sapi dengan kepadatan lalat tinggi.

Menurut Depkes RI (1995), interpretasi hasil pengukuran indeks populasi lalat pada setiap lokasi (Blok Grill) sebagai berikut :
a. 0-2 : Rendah atau tidak menjadi masalah
b. 3-5 : Sedang dan perlu dilakukan penga- manan terhadap tempat-tempat ber- kembangbiakan lalat (tumpukan sampah, kotoran hewan dan lain-lain)
c. 6-20 : Tinggi/ padat dan perlu pengamanan terhadap tempat-tempat berkembang- biakan lalat dan bila mungkin diren- canakan upaya pengandaliannya
d. >21 : Sangat tinggi/ sangat padat dan perlu dilakukan pengamanan terhadap tempat-tempat perkembangbiakan lalat dan tindakan pengendalian lalat

Menurut Chaasan Sudjani (2001) agar mengurangi atau menekankan indeks kepdatan lalat yang tinggi dilakukan pengendalian lalat, yaitu dengan cara pengendalian secara fisik, kimia dan mekanik tetapi pengendalian lalat ini hanya bersifat sementara. Bagi 7 kandang sapi yang indeks kepadatan lalat tinggi dilakukan pengendalian dengan cara mencuci kandang setiap harinya, memandikan hewan setiap harinya, membuang kotoran sapi ke penam-pungan setiap hari, dan dilakukan desinfeksi kandang agar tidak terjadi kepadatan lalat tinggi, untuk 3 kandang sapi yang indeks kepa-datan lalat sedang, dilakukan member-sihkan kandang setiap harinya. c. Analisis Statistik

Tabel 4: Uji Korelasi Spearman Hubungan Sanitasi Kandang dengan Kepadatan Lalat

\begin{tabular}{|l|r|r|r|r|}
\hline & Value & $\begin{array}{c}\text { Asymp. } \\
\text { Std. }\end{array}$ & $\begin{array}{c}\text { Approx } \\
. \mathrm{T}^{\mathrm{b}}\end{array}$ & $\begin{array}{c}\text { Appr } \\
\text { ox. } \\
\text { Sig. }\end{array}$ \\
\hline $\begin{array}{l}\text { Interval by Interval } \\
\begin{array}{l}\text { Pearson's R } \\
\text { Ordinal by Ordinal } \\
\text { Spearman Correlation }\end{array}\end{array}$ & -.76 & .297 & -191 & $.853^{\mathrm{c}}$ \\
\cline { 1 - 3 } N of Valid Cases & 10 & .307 & -111 & $.915^{\mathrm{c}}$ \\
\hline
\end{tabular}

Hasil analisis hubungan sanitasi kandang sapi dengan kepadatan lalat di kan-dang sapi Kecamatan Sokaraja Kabupaten Banyumas menggunakan metode uji korealis spearman, dengan aplikasi pengolah data statistic menunjukkan Korelasi Koefisien sebesar 0,076. > 0,05 artinya HA ditolak dan H0 diterima, yang berarti tidak ada hubungan sanitasi kandang dengan kepadatan lalat di kandang sapi.

Hal ini dimungkinkan karena angka rata-rata kondisi sanitasi kandang sapi ada yang kurang baik dan adapula cukup baik, sehingga terdapat perbedaan kepadatan lalat yang tidak signifikan. Hal-hal yang memperoleh H0 diterima, yaitu jumlah sapi, kondisi peternakan sapi yang berbeda, serta musim buah.

\section{Kesimpulan}

Berdasarkan hasil penelitian dan pem-bahasan dapat ditarik kesimpulan sebagai berikut :

a. Petugas kandang melakukan pembersihan kandang dengan cara menyiram air, lalu untuk membersihkan pakan dan minum ternak dilakukan dengan cara manual meng-gunakan tangan dan kain lap dan untuk kotoran dimasukan ke dalam karung penam-pung kotoran.

b. Sanitasi kandang sapi di Kecamatan Sokaraja Kabupaten Banyumas yang meme-nuhi syarat ada 7 kandang dan 3 kandag tidak memenuhi syarat.

c. kepadatan lalat pada kandang sapi di Kecamatan Sokaraja Kabupaten Banyumas adalah 4 ekor/blok grill (sedang) dan 5 ekor/blok grill (sedang).

d. Berdasarkan analisis statistik dinyatakan bahwa tidak ada hubungan sanitasi kandang dengan kepadatan lalat pada kandang sapi di Kecamatan Sokaraja Kabupaten Banyumas.

\section{Saran}

a. Kepada pemilik kandang disarankan dapat lebih meningkatkan sanitasi kandang sapi dalam hal pemberian APD, pencegahan kepadatan lalat, pembersihan kandang, pengelolaan limbah. Dengan diadakan pe-maparan hasil penelitian dan bekerjasama dengan pihak terkait.

b. Melakukan perencanaan, pelaksanaan serta pembangunan bidang kesehatan lingkungan 
khususnya pada kandang ternak agar tidak menyebabkan ganguan penyakit yang dibawa oleh lalat kepada manusia.

c. Hasil penelitian ini diharapkan dapat menjadi sumber referensi dan pustaka di perpustakaan berkaitan dengan hubungan sanitasi kandang sapi dengan kepadatan lalat.

d. Bagi peneliti yang akan datang disarankan juga meneliti variabel-variabel lain yang berkaitan dengan faktor-faktor yang mempengaruhi kepa-datan lalat, selain sanitasi kandang sapi.

\section{Daftar Pustaka}

Agus Suwarni. 2012. Menghitung Kepadatan Lalat. Universitas Indonesia, Depok Jawa Barat https://www.acedemia.edu//menghitung_kepa datan_lalat

Aninur Rasyid Hartati. 2007. Petunjuk Teknis Perkandangan Sapi Potong, Pasuruan Jawa Timur

Aris Santjaka. 2011. Statistik untuk Penelitian Kesehatan, Yogyakarta

Azwar, A. 1995. Pengantar Kesehatan Lingkungan. Jakarta : PT. Rineka Cipta.

Depkes RI., 1995. tentang Pemberantasan Lalat, Direktorat Jenderal PPM\&PL Departemen Kesehatan Republik Indonesia. 1995. Jakarta: Depkes RI.

Chasan Sudjani Kusnadi, MKM, 2001. Pengendalian vektor dan Binatang Pengganggu (Vektor Control Manual). Makasar Sulawesi Selatan

Departemen Kesehatan RI, 2001. Derektorat Jenderal Pengendalian lalat Pember-antasan Penyakit Menular dan Penyehatan lingkungan

Direktorat Jenderal Peternakan, 2000. Budidaya Sapi Potong yang Baik. Jakarta

Farida. S. M. dan Kaharudin. 2010. Petunjuk Praktis Perkandangan Sapi. Balai Pengkajian Teknologi Pertanian Ntb. Mataram

Heri Suprapto, 2010. Cara Tepat Penggemukan Sapi Potong. Tanggerang Banten

Indra Gunawan, 2006. Pengetahuan Masyarakat tentang Pengelolaan Sanitasi Berbasis Masyarakat, Semarang Jawa Tengah.

Kementerian Keseshatan RI, 2011. Buku Pedoman Pengendalian Penyakit Diare. Direktorat Jenderal Pengendalian Penyakit dan Penyehatan Lingkungan.

Luthviatin Novia, 2012. Dasar-Dasar Promosi Kesehatan dan Ilmu Prilaku, Jember Jawa Timur.
Nur Nasry, 2008. Epidemiologi, Jakarta : Rineka Cipta

Peraturan Pemerintah Republik Indonesia, Nomor 66 Tahun 2014. tentang Kesehatan Lingkungan.

Peraturan Pemerintah Republik Indonesia, Nomor 95 Tahun 2012. tentang Kesehatan masyarakat Veteriner dan Kesejahteraan Hewan.

Peraturan Presiden, Nomer 72 Tahun 2012. Tentang Sistem Kesehatan Nasional

https://s3.amazonaws.com/academia.edu.document s/39022383/01_Slide

\section{SKN 2012_LITBANGKES.pdf/}

Peraturan Menteri Pertanian, Nomor 55 Tahun 2006. Pedoman Pembibitan Sapi Perah yang Baik

Puji Lestari, 2008. Hubungan Antara Kondisi Sanitasi dengan Kejadian Diare pada Peternak Sapi Perah di Desa Singosari Kecamatan Mosongo Kabupaten Boyolali, Universitas Muhamadiyah Surakarta.

Sarwono, B, 2012. Beternak Kambing Unggul. Jakarta : Penebar Swadaya

Tresiana Marpaung, 2018. Kondisi Sanitasi Kandang Ternak, Kepadatan Lalat, Pengetahuan, dan Sikap Masyarakat di Desa Urat Timur Kecamatan Palipi 